\title{
A Residência Multiprofissional em Saúde: expectativas de ingressantes e percepçóes de egressos
}

| ${ }^{1}$ Ester Martins Carneiro, ${ }^{2}$ Lívia Maria Silva Teixeira, ${ }^{4}$ José Ivo dos Santos Pedrosa I

Resumo: A Residência Multiprofissional em Saúde é uma modalidade de treinamento em serviço que tem como base a aprendizagem de atributos técnicos e relacionais pela prática cotidiana, com vistas ao aperfeiçoamento do SUS. O presente estudo objetiva conhecer expectativas de residentes multiprofissionais e compará-las com as percepçóes de egressos. Utilizou-se o método qualitativo e, para a produção dos dados, foi feita entrevista não diretiva com 12 ingressantes e um grupo focal com sete egressos. Os relatos dos ingressantes geraram uma categoria geral "expectativas", de onde foram desveladas quatro subcategorias: pessoais, profissionais, relacionais, estruturais / organizativas. As percepçóes produzidas nos egressos evidenciaram que expectativas quanto ao conhecimento teórico, trabalho multiprofissional, relação com residentes da RMS, com profissionais e preceptores foram aquém do esperado. Já as expectativas quanto ao preparo e autoconfiança profissional, conhecimento prático, inserção no mercado de trabalho, carga horária e infraestrutura do hospital foram atingidas no transcorrer dos dois anos desse tipo de pós-graduação. $\mathrm{O}$ conhecimento das expectativas e percepçóes de residentes permite uma avaliação da Residência e pode oportunizar melhorias no planejamento e execução do ensino, e, por conseguinte, na qualidade do programa.

> Palavras-chave: Residência Multiprofissional; Residência em Saúde; ensino em saúde; capacitação em serviço.

\author{
1 Universidade Federal do Piauí \\ Teresina-PI, Brasil (estermartinsc@ \\ hotmail.com). \\ ORCID: 0000-0002-1706-5199 \\ ${ }^{2}$ Universidade Federal do Piauí. \\ Teresina-PI, Brasil (liviamst@ \\ yahoo.com.br). \\ ORCID: 0000-0002-8462-6953 \\ ${ }^{3}$ Universidade Federal do Piauí. \\ Teresina-PI, Brasil (jivopedrosa@ \\ gmail.com). \\ ORCID: 0000-0002-5416-2860
}

Recebido em: 14/08/2019

Aprovado em: 04/05/2020 Revisado em: 13/07/2021 


\section{Introdução}

As ações e serviços de saúde no Brasil integram uma rede regionalizada e hierarquizada e constituem o Sistema Único de Saúde (SUS), o qual foi instituído pela Constituição Federal de 1988 e regulamentado pelas Leis no 8.080/90 e no 8.142/90, Leis Orgânicas da Saúde. O SUS tem como uma de suas diretrizes o atendimento integral e, entre suas competências, a de ordenar a formação de recursos humanos na área da saúde. É com este propósito que o programa de Residência Multiprofissional em Saúde (RMS) entra no cenário nacional, oficialmente instituído pela Lei no 11.129 de 30 de junho de 2005. Orientado pelos princípios e diretrizes do SUS a partir das necessidades e realidades locais e regionais, o programa propóe que a mudança na formação do profissional da saúde irá gerar implementações positivas no atual modelo de assistência à saúde (LANDIM; SILVA; BATISTA, 2012; JREIGE, 2013).

A RMS é uma modalidade de pós-graduação lato sensu que tem como objetivo a formação de profissionais para uma atuação diferenciada no SUS, com construção interdisciplinar, trabalho em equipe, educação permanente e consequente reorientação das lógicas tecnoassistenciais. Abrangendo as áreas da Enfermagem, Farmácia, Fisioterapia, Fonoaudiologia, Nutrição, Odontologia, Psicologia, Serviço Social e Terapia Ocupacional, o programa foi estabelecido com duração mínima de dois anos, carga horária total de 5.760 horas, sendo $80 \%$ de atividades práticas e $20 \%$ de atividades teóricas ou teórico-práticas, em 60 horas semanais, priorizando as atividades hospitalares e em Atenção Primária à Saúde. Dessa forma, os residentes são formados para prestar assistência aos pacientes em equipe multiprofissional, possibilitando uma maior integralidade e humanização da atenção (SILVA et al., 2013; 2015).

O processo de formação dos profissionais da saúde constitui um desafio a gestores e educadores devido à complexidade de estimular ao mesmo tempo habilidades profissionais, interpessoais e humanísticas, além de apurado senso crítico sobre responsabilidade social no aluno. Os programas de RMS apresentam caráter de vanguarda em nosso país ao incentivarem práticas multiprofissionais ativas e participativas na atenção em saúde (SANCHES, 2016).

A Residência é uma oportunidade significativa de aprendizado e contato com outras áreas da saúde, o que estimula anseios, percepções e expectativas em relação ao conhecimento teórico-prático adquirido e seu reflexo na atuação laboral. Esta pesquisa busca avaliar um programa de RMS por meio do conhecimento das expectativas 
dos ingressantes e comparação com as percepçôes dos egressos. Os resultados desse trabalho avaliativo conduzirão a uma compreensão da realidade de ensino e de assistência vivenciada pelos residentes, o que contribuirá agregando conhecimento no processo de formação desses profissionais para o mercado de trabalho.

\section{A Residência Multiprofissional em Saúde}

O termo residência surgiu em 1889, no hospital da universidade norte-americana John Hopkins, como uma forma de capacitação profissional para médicos, chegando ao Brasil na década de 1940 com a criação do primeiro programa de residência médica no Hospital das Clínicas da Faculdade de Medicina da Universidade de São Paulo (USP). O bom funcionamento da Residência Médica serviu de modelo para expandir-se em outras áreas da saúde, e, a partir da década de 1960, começaram a ser criados programas similares para capacitação de outros profissionais da saúde com a finalidade de qualificar seus membros através do treinamento, em atividades de longa duração, nos mesmos parâmetros da Residência Médica. Em 1961, foi criado o primeiro Programa de Residência em Enfermagem, no Hospital Infantil do Morumbi, em São Paulo. Em 1973 iniciou-se o segundo curso de especialização nos moldes de Residência em Enfermagem, formando enfermeiros especialistas na área médico-cirúrgica pelo Hospital Escola da Faculdade de Enfermagem da Universidade Federal da Bahia (JREIGE, 2013; SELTENREICH, 2017; SILVEIRA, 2011).

Em 1976, foi criada no Brasil, pela Secretaria Estadual de Saúde do Rio Grande do Sul, em sua Unidade Sanitária denominada São José do Murialdo, a primeira Residência em Medicina Comunitária. Sua proposta incluía formar profissionais com uma visão de saúde clínica, saúde mental e saúde pública, com perfil humanista e crítico, com competência para uma boa resolubilidade das necessidades de saúde da comunidade. Dois anos depois, a Residência do Murialdo se tornou multiprofissional (BRASIL, 2006).

Outras experiências multiprofissionais foram consideradas pioneiras na década de 1970, como o Treinamento Avançado em Serviço (TAS) da Escola Nacional de Saúde Pública da Fundação Oswaldo Cruz (ENSP-FIOCRUZ), e o Programa de Apoio às Residências de Medicina Preventiva, Medicina Social e Saúde Pública (PAR-MP/MS/SP), criado pelo Instituto Nacional de Assistência Médica da Previdência Social (INAMPS) (BRASIL, 2006; ROMCY, 2018) 
Após a criação do SUS, a necessidade de adoção de outras estratégias de formação fez com que, em 2002, juntamente com o lançamento do Projeto de Expansão e Consolidação da Saúde da Família (PROESF) para municípios com mais de 100 mil habitantes, que visava qualificar e capacitar as equipes de saúde da família, fosse produzida a primeira iniciativa do Ministério da Saúde de fomento à RMS, com a criação de 19 residências multiprofissionais em saúde da família, vinculadas a instituiçóes de ensino superior, que ficaram responsáveis por sua criação e titulação. Com formatos diversificados, essas residências existiram dentro da perspectiva de trabalhar integradamente com todas as profissóes da saúde (BRASIL, 2006; ROMCY, 2018).

A 12a Conferência Nacional de Saúde, que aconteceu em Brasília de 7 a 11 de dezembro de 2003, indicou a formulação de uma política de formação para os profissionais da saúde, com o objetivo de discutir e implementar mudanças no processo de ensino na pós-graduação (especialização/residência), para que atendessem às necessidades de saúde da população e aos princípios e diretrizes do SUS, com garantia de recursos físicos e financeiros, com cooperação técnica entre as três esferas de governo, e com controle social. E em 2004, após vários debates e construção coletiva, o Ministério da Saúde instituiu, pela Portaria no 198/GM/ MS, a Política Nacional de Educação Permanente em Saúde (PNEPS). A Educação Permanente em Saúde (EPS) é aprendizagem no trabalho, onde o aprender e o ensinar se incorporam ao quotidiano das organizaçôes. Propóe-se que os processos de capacitação dos trabalhadores da saúde, desde o nível técnico até a pós-graduação, tomem como referência as necessidades de saúde das pessoas e transformem as práticas profissionais e a própria organização do trabalho (BRASIL, 2004; 2007).

Nesse contexto, em 30 de junho de 2005, foi promulgada a Lei no 11.129 que instituiu a Residência em Área Profissional da Saúde e criou a Comissão Nacional de Residência Multiprofissional em Saúde (CNRMS), com eixos norteadores como: 1) cenários de educação em serviço representativos da realidade socioepidemiológica do país; 2) concepção ampliada de saúde que respeite a diversidade; 3) política nacional de gestão da educação na saúde para o SUS; 4) abordagem pedagógica que considere os atores envolvidos como sujeitos do processo de ensino-aprendizagemtrabalho e protagonistas sociais; 5) integração ensino-serviço-comunidade, por intermédio de parcerias dos programas com os gestores, trabalhadores e usuários; 6) integração de saberes e práticas que permitam construir competências 
compartilhadas para a consolidação da educação permanente, tendo em vista a necessidade de mudanças nos processos de formação, de trabalho e de gestáo na saúde; 7) descentralização e regionalização, contemplando as necessidades locais, regionais e nacionais de saúde (BRASIL, 2005; 2009).

No ano de 2005, o Ministério da Saúde financiava 22 programas de Residência Multiprofissional em Saúde da Família (RMSF) em funcionamento no Brasil, num total de 1.558 residentes de diversas categorias. Esses programas estavam distribuídos em vários estados do país e possuíam configuração variada, obedecendo a demandas locais e aos projetos das instituiçôes formadoras (DEGIOVANI, 2017).

A construção da RMS, com uma série de compromissos por uma saúde ampliada e dentro dos princípios do SUS, assegurou um campo de possibilidades, contudo necessita continuamente de autoanálise e de questionamento de si (FARIAS, 2016).

\section{Proposta metodológica}

Foi realizada uma pesquisa de abordagem qualitativa de caráter exploratório e descritivo, por meio dos métodos da entrevista não-diretiva e grupo focal, com a RMS da Universidade Federal do Piauí (RMS-UFPI), localizada no município de Teresina, estado do Piauí. O programa existe há seis anos e, em maio de 2019, havia duas turmas em andamento, 24 profissionais matriculados e quatro turmas concluídas, totalizando 40 residentes multiprofissionais formados. A cada ano são ofertadas 14 vagas por meio de edital público.

Participaram do estudo 12 residentes ingressantes do ano de 2018 e sete egressos do ano de 2019, totalizando 19 participantes, com disponibilidade e interesse em participar da pesquisa. A coleta de dados foi feita em local privativo em salas cedidas pelo Hospital Universitário da UFPI (HU-UFPI), campo de atuação dos residentes, em dias e horários mais adequados às suas rotinas.

Com os ingressantes foi utilizada a entrevista não diretiva com a seguinte questão norteadora: “Quais são suas expectativas em relação à RMS-UFPI?”. E com os egressos foi feito um grupo focal com as questóes disparadoras: 1) Como foi o processo de aprendizado na RMS-UFPI? Vocês se sentiram motivados? 2) E agora com o fim da RMS-UFPI, como vocês se sentem para atuarem no mercado profissional? Vocês acham que adquiriram novas competências? 3) Que elementos estiveram presentes nesse processo? 
As falas dos participantes foram transcritas na íntegra no software Word 2010, lidas e analisadas pelos pesquisadores. Foi utilizada a análise de conteúdo do tipo temática proposta por Bardin. Essa análise busca, através da expressão dos indivíduos, categorizar núcleos de texto que se repetem possibilitando a realização de inferências (BARDIN, 1977; CAREGNATO; MUTTI, 2006).

A pesquisa foi autorizada pela Comissão de Ética em Pesquisa do HU-UFPI com Carta de Aprovação no 34/18, e aprovada pelo Comitê de Ética em Pesquisa da UFPI sob parecer $n^{o}$ 2.868.973. Todos os participantes assinaram o Termo de Consentimento Livre e Esclarecido em duas vias, uma do participante e a outra do responsável pela pesquisa, em consonância com a resolução n466/12 do Conselho Nacional de Saúde.

\section{Expectativas dos ingressantes}

Após a transcrição e análise das entrevistas com os residentes ingressantes, surgiu a categoria "expectativas", de onde se originaram quatro subcategorias: pessoais, profissionais, relacionais e estruturais/organizativas (quadro 1).

Quadro 1. Categorizaçấo dos discursos dos residentes ingressantes

\begin{tabular}{|c|c|c|}
\hline CATEGORIA & SUBCATEGORIAS & UNIDADES DE REGISTRO \\
\hline \multirow[t]{12}{*}{ Expectativas } & Pessoais & Amadurecimento \\
\hline & \multirow[t]{5}{*}{ Profissionais } & Novas experiências \\
\hline & & Conhecimento \\
\hline & & Inserção no mercado de trabalho \\
\hline & & Segurança/autoconfiança profissional \\
\hline & & Trabalho em equipe multiprofissional \\
\hline & \multirow[t]{4}{*}{ Relacionais } & Residentes da RMS \\
\hline & & Residentes médicos \\
\hline & & Profissionais do hospital \\
\hline & & Preceptores \\
\hline & \multirow[t]{2}{*}{ Estruturais/Organizativas } & Carga horária \\
\hline & & Estrutura do hospital \\
\hline
\end{tabular}

Fonte: Dados da pesquisa, 2019. 
Da subcategoria "expectativas pessoais" emergiu a unidade de registro "amadurecimento pessoal". Os pesquisados apontam que a RMS-UFPI é uma possibilidade de amadurecimento e crescimento pessoal por meio do convívio com pacientes, profissionais, famílias e grupos.

Eu acredito que ficar em um ambiente aonde eu vou estar constantemente fazendo ajustamentos criativos [...] eu vou lidar com grupos, vou lidar com famílias, com os profissionais [...] isso vai me trazer um amadurecimento pessoal, quanto uma segurança com relação a lidar com questôes próprias, dificuldades pessoais. (Residente 8)

A subcategoria "expectativas profissionais" gerou cinco unidades de registro: ganho de experiência, conhecimento, segurança/autoconfiança profissional, inserção no mercado de trabalho, trabalho em equipe multiprofissional.

Na parte de experiência, a gente sai (da graduação) com muitos medos, muitos receios. Então eu pretendo perder isso. (Residente 1)

Quando eu vi o edital da residência multiprofissional me veio [...] uma experiência que eu não vivenciei durante minha formação, não tive estágio de psicologia hospitalar. (Residente 8)

Os residentes demonstram anseio por experiência profissional e veem na RMS uma maneira de adquiri-la. Eles percebem a importância de experenciar a rotina do ambiente hospitalar, visto que para alguns, isso foi uma novidade.

A RMS tem como objetivos o aperfeiçoamento progressivo do padrão profissional e científico dos residentes e a melhoria da assistência à saúde da comunidade nas áreas profissionalizantes (COREMU-UFPI, 2017). Foi unânime a opinião dos entrevistados de que a RMS-UFPI lhes proporcionará aquisição de conhecimento, seja teórico ou prático, não só de suas profissóes, como das demais áreas.

A presença dentro do hospital e com a equipe multiprofissional como um todo, eu acredito que o hospital vá me trazer muito conhecimento em sentido técnico e prático. (Residente 9)

No trabalho em saúde, o desenvolvimento de competências envolve a transmissão de informação, a construção do conhecimento, a aquisição do saber em cenários de prática, a aprendizagem em situaçóes reais de trabalho e a capacidade de ser afetado pelos signos que informam o cotidiano e as necessidades sociais em saúde. A competência é como a inteligência que vem depois, não é o que se prescreve como prática desejada ou desejável, mas aquilo que foi contatado, experenciado, apreendido, de forma corporal e sensorial (CECCIM, 2012). 
O programa de RMS é visto como uma oportunidade de eles adquirirem mais segurança para a atuação profissional. Essa "sensação de imaturidade" dificulta o exercício da profissão e a inserção no mercado de trabalho.

A gente sai da universidade muito cru na parte de experiência. (Residente 1)

Quanto às expectativas profissionais de inserção no mercado de trabalho, os residentes tem na RMS-UFPI um meio de aprimoramento do currículo com o título de especialista, logo eles percebem que é necessária a continuidade da formação para o desenvolvimento de uma melhor prática profissional.

O que me fez também fazer a residência, a prova, foi o mercado de trabalho [...] eu acredito que abriria muitas portas para mim, em outros hospitais particulares, mas também me dando a possibilidade de tentar um concurso. (Residente 8)

Os depoimentos demonstram que a construção da multiprofissionalidade ainda representa um desafio. Com a visão do trabalho em equipe, é possível a criação de novos espaços que se originam das práticas no território, das trocas de saberes, de experiências e de transformaçáo, mediante a corresponsabilidade pelo projeto terapêutico, sem a existência de uma rivalidade corporativa (CASANOVA; BATISTA; MORENO, 2018).

A residência vai fazer com que eu tenha mais contato com os profissionais de outras áreas, que a gente consiga trabalhar realmente o trabalho multiprofissional que é muito importante. (Residente 5)

Da subcategoria "expectativas relacionais" emergiram 4 unidades de registro: com os residentes da RMS, com os residentes médicos, com os profissionais do hospital e com os preceptores. Pela fala da maioria, as expectativas de relacionamento com os residentes da RMS-UFPI eram baixas, e alguns acreditavam que seria semelhante ao distanciamento que vivenciaram com profissionais médicos em experiências anteriores.

Tinha uma expectativa mais baixa com relação aos residentes da multi. (Residente 8)

Eu acreditava que seria da mesma forma que é com os médicos, essa dificuldade de conseguir interagir com as demais áreas e de reconhecer que cada um tem a sua importância no cuidado do paciente. (Residente 10)

Em relação aos profissionais do hospital, as expectativas foram de encontrar pessoas preparadas que se dispusessem a compartilhar conhecimentos e práticas. A maioria ressaltou a importância de recursos humanos qualificados no cenário de aprendizagem, não só dos preceptores do programa, como dos profissionais do hospital. 


\begin{abstract}
A minha expectativa era essa de que eu encontrasse pessoas preparadas, por se tratar de um hospital escola, e pessoas que fossem me dar um embasamento teórico junto com passar a rotina. (R7)
\end{abstract}

O preceptor éo profissional de saúde que oferece treinamento prático em ambientes de serviços de saúde e possui duplo papel: atua como profissional na assistência em saúde e, ao mesmo tempo, assume o compromisso de ensinar, orientar, supervisionar e servir como modelo para o estudante. As atividades educacionais do preceptor estão voltadas para o desenvolvimento de um perfil ancorado na integralidade do cuidado e na equidade da atenção, em consonância com as diretrizes do SUS (DIAS et al., 2015). Conforme os depoimentos, as expectativas dos residentes coadunam com todos esses papéis do preceptor.

Eu espero encontrar nos meus preceptores esse apoio pra tirar essas dúvidas, pra tirar esses medos em relação a uma intervenção, uma intercorrência. (Residente 1)

A subcategoria "estruturais/organizativas" foi composta pelas unidades de registro: carga horária e estrutura do hospital. No que tange à carga horária, os residentes tinham expectativas de que seria exaustiva e que eles teriam de abrir mão de muitas coisas para cumpri-la.

A gente sabe que é realmente exaustiva, são 12 horas diárias, 60 horas semanais, mas é realmente o que é esperado. (Residente 12)

As expectativas quanto à estrutura do hospital foram muito boas em todos os relatos, e os residentes consideram o HU-UFPI o melhor hospital público da região, nesse aspecto. Eles também associaram o hospital à instituição de ensino superior à qual ele é vinculado, no caso à UFPI.

A UFPI em si já tem um nome [...] e eu vejo aqui (HU) como um dos melhores hospitais públicos de Teresina, então nessa parte do ambiente hospitalar eu creio que não tenha muitas falhas como os outros hospitais públicos daqui. (Residente 1)

\title{
Percepçóes dos egressos $\mathrm{x}$ expectativas dos ingressantes
}

Quanto ao conhecimento adquirido, os egressos em unanimidade afirmaram que a aprendizagem do ponto de vista teórico foi deficitária. Logo, aquela expectativa alta dos ingressantes não foi suprida em sua totalidade ao longo da residência, visto que, na perspectiva dos egressos, o aprendizado prático foi superior, em detrimento do teórico, que ficou prejudicado. 


\begin{abstract}
A gente tem sempre a mesma rotina de ir lá e escutar o paciente, e fazer o nosso trabalho, e eu acho que nesse sentido tem aprendizagem, aprendizagem prática [...] a gente passa dois anos fazendo a mesma coisa, então a gente acaba criando as nossas habilidades, estudando as coisas que a gente tem dificuldade, enfim. Mas em relação a ter aquele suporte teórico que você imagina que vai ter, pelo menos no início, não. (Egresso 7)
\end{abstract}

Com relação ao preparo/segurança profissional obtidos com a Residência, percebese a existência de uma dicotomia entre teoria e prática. Os egressos relatam que essa segurança adquirida foi mais no sentido prático, e que o teórico ficou aquém das expectativas iniciais relatadas pelos ingressantes. Nessa ambiência, eles apontam que, apesar das dificuldades encontradas, a Residência oportunizou ganho de experiência e desenvolvimento de habilidades e, dessa forma, crescimento pessoal e profissional.

Eu me sinto mais preparada, mas não no sentido do conhecimento teórico em si que eu adquiri aqui, mas da convivência, das relaçóes interpessoais, em como você lida com um ambiente que não é muito saudável pra você. (Egresso 6)

Os egressos entendem que a RMS irá contribuir para a inserção deles no mercado de trabalho. Essa percepçáo corrobora com as expectativas dos residentes entrevistados que viam na conclusão da RMS possibilidades maiores de emprego e de inserção profissional.

Em qualquer seleção que você vai participar eles perguntam "Você tem experiência em que? Aonde? Você já fez o que?” Entâo, assim, o HU é um hospital grande, é um hospital que tem um nome [...] pode ser o seu diferencial. (Egresso 4)

De fato, a Residência oferece uma visão que transcende o atendimento clínico, ela o contempla, porém com ênfase ao acolhimento, ao trabalho em grupo, à vigilância em saúde e ao trabalho interdisciplinar. Esse perfil da Residência prepara o profissional para ofertar um atendimento mais humanizado, focando não somente no estado de doença da pessoa, mas inter-relacionando com o meio em que está inserido. Assim, o profissional egresso da RMS tem um diferencial em seu currículo, visto que possui formação pautada nos valores e diretrizes propostos pelo SUS (OLIVEIRA et al., 2017).

No que tange ao trabalho em equipe multiprofissional, muitos destacaram que a multiprofissionalidade não acontecia na maioria das vezes, pelo tamanho do hospital e pelo fato de muitos profissionais ficarem restritos aos seus núcleos profissionais, e de o diálogo entre as diversas categorias ainda não ser uma prática cotidiana.

Eu não via isso de multiprofissionalidade, e até pela questão de estrutura do hospital, em muitos setores a gente não tinha essa multiprofissionalidade. (Egresso 2) 
Evidencia-se a necessidade de transformação do trabalho isolado em coletivo no qual se tem o reconhecimento do serviço do outro, pois é no exercício multiprofissional e interdisciplinar que acontece a apreensão dos múltiplos conhecimentos e práticas onde as açóes se convergem e o trabalho em equipe se torna realidade (SILVA et al., 2015).

A educação dos profissionais de saúde vem sendo (re)discutida amplamente no mundo e, de acordo com a Organização Mundial da Saúde (OMS), ainda é considerada fragmentada, descontextualizada e produtora de um currículo estático. As Residências emergem como possibilidade de problematização da realidade no cotidiano dos serviços de saúde e de articulação destes com as instituições de ensino em busca da integração de residentes, docentes, usuários, gestores, trabalhadores e profissionais de saúde. Além de possibilitar a permeabilidade das ações educativas no cotidiano das práticas de saúde, vislumbrando o desenvolvimento da Educação Permanente em Saúde (EPS) aos profissionais vinculados aos serviços de saúde (ARNEMANN et al., 2018).

No tocante ao relacionamento entre os residentes da RMS, os egressos salientaram que havia uma ótima relação e comunicação entre eles, que a convivência do grupo de residentes multiprofissionais era permeada pela gentileza, o que vai de encontro ao relato da maioria dos ingressantes, os quais afirmaram terem expectativas baixas no que diz respeito à relação com os residentes da RMS-UFPI.

Geralmente a gente se comunicava nos grupos, por exemplo: "Ah eu quero saber informação sobre o paciente tal". Então a gente sempre procurava uns aos outros, e não a outros profissionais, entendeu? Porque a gente sabia que era muito mais fácil a gente se ajudar, do que outras pessoas ajudarem. (Egresso 6)

Já o relacionamento com os residentes médicos era, na maioria das vezes, uma relação distante, o mesmo esperado pelos ingressantes entrevistados. Eles tinham baixas expectativas devido a vivências anteriores com profissionais dessa área. Os relatos apontam para a concentração das práticas na figura do médico, e a persistência da visão médico-centrada.

Depende da pessoa, porque nem todos eram abertos, nem todos eram sensíveis no sentido de a gente chegar e falar alguma coisa e a pessoa realmente parar e te dar credibilidade. Porque alguns ou "entrava no ouvido e saia no outro", ou achava que sabia mais do que qualquer um de nós. Mas alguns poucos eram abertos a escutar a gente, a discutir algum caso, a levar em consideração o que a gente tava falando. (Egresso 6) 
São de fundamental importância medidas voltadas à horizontalização das relaçóes estabelecidas entre profissionais de saúde de diferentes categorias, em um movimento que busque valorizar todos os saberes, compreendendo-os como complementares, e não sobrepostos (BAQUIÃO et al., 2019).

No que concerne aos profissionais do hospital, as opinióes dos egressos foram no sentido de que a relação com eles seria de divisão do trabalho e não de parceria. Isso está em desacordo com as expectativas dos ingressantes, as quais foram muito boas nesse critério.

Os profissionais que atuavam junto com a gente, eles queriam a gente pra dividir o serviço com eles, e não pra dividir o conhecimento que eles tinham do serviço com a gente. (Egresso 7)

No hospital, o cuidado ao paciente é o produto de um grande número de pequenos cuidados parciais, que vão se complementando, de forma explícita ou implícita, a partir da interação entre vários profissionais. Assim, uma complexa trama de atos, procedimentos, fluxos, rotinas, saberes, num processo de complementação e disputa, compóem o cuidado em saúde. A forma como se articulam as práticas dos trabalhadores do hospital confere maior ou menos integralidade à atenção produzida (FEUERWERKER; CECÍLIO, 2007).

Os egressos afirmaram ter uma melhor relação com profissionais administrativos e de nível médio. Com os de nível superior, a relação era verticalizada e havia uma suposta hierarquia que, se não respeitada, geraria problemas para eles, residentes. Os profissionais de nível superior do HU-UFPI não se viam no mesmo nível que os residentes, e muitos interpretavam esse contato como uma cobrança, segundo os relatos:

Os funcionários, que são geralmente auxiliares administrativos, eles são mais receptivos. Agora, os funcionários de nível superior nem todos são e, às vezes, eles interpretam nosso contato como uma cobrança. (Egresso 7)

Segundo Peres et al. (2011), a hierarquia existente entre os profissionais que constituem uma equipe tende a ser um obstáculo, na medida em que envolve a delimitação da área de atuação e dos procedimentos que podem ser executados por cada um, assim como a defesa de espaços conquistados e dos privilégios adquiridos. Essa hierarquia pode ser manifestada de diversas maneiras, ensejando disputas de poder - quer sejam elas veladas ou declaradas - no que se refere à tomada de decisão sobre as condutas técnicas. $\mathrm{O}$ ingresso dos residentes no setor em questão, 
promovendo o compartilhamento de liderança nos processos decisórios, pode ser capaz de conduzir a uma insatisfação de certos anseios individuais anteriormente satisfeitos. Mas essa situação pode ser manejada de maneira satisfatória por meio de um diálogo aberto e cooperativo.

Com relaçáo à preceptoria, os egressos foram convergentes no que se refere à ausência desse acompanhamento. Isso destoa dos discursos dos ingressantes, que esperavam encontrar no preceptor esse suporte profissional e teórico. Muitos egressos não contavam com preceptores em todos os cenários de prática.

"A pessoa está afastada, a pessoa está de licença, a pessoa não atua na área, ela fica na
divisão de enfermagem", então, como é que o preceptor está na divisão de enfermagem e
vai ser meu preceptor no posto 3? [...] Eu só soube mesmo da minha preceptoria da UTI,
somente. (Egresso 4)

Ficou evidenciado na RMS-UFPI que essa supervisão ocorria a partir de dúvidas, de demandas e de profissionais específicos. Dependia do preparo e disposição particulares de cada preceptor. Percebe-se um hiato entre o que preconiza o MEC e a forma como as ações estão se efetivando.

Algumas pessoas eram bem mais dispostas a ensinar, por exemplo, eu tenho uma dúvida, ela ia discutir com você, ela ia tentar ajudar, ela ia te incentivar, "Pesquisa sobre isso!", mas tipo assim uma ou duas pessoas de 12, entendeu? (Egresso 6)

Náo reconhecer o processo de ensino como inerente à prática, pode levar o preceptor a simplesmente delegar suas atividades ao residente e não estabelecer uma verdadeira relação pedagógica. É mister que o preceptor compreenda que, enquanto prática educativa, sua atividade demanda planejamento, competência e criatividade (TORRES et al., 2019). Dessa forma, o exercício da preceptoria, deve estimular a reflexão dos profissionais sobre suas práticas nos espaços de formação e trabalho, pois a presença do ensino nos serviços de saúde gera um potencial questionador sobre as práticas instituídas (SOUZA; FERREIRA, 2019).

Cavalcanti e Sant'Ana (2014), em estudo descritivo-exploratório com 210 preceptores de uma RMS, identificaram que as carências e dificuldades da preceptoria na residência multiprofissional podem ser reunidas em duas principais vertentes: a falta de capacitação didático-pedagógica e a ausência de definição institucional formal sobre a atividade de preceptoria, enquanto atuação profissional. O preceptor, profissional da área de saúde que não é da academia, a despeito de desempenhar um importante papel na integraçáo do recém-graduado no contexto do ensino em 
serviço, quase sempre carece de formação didático-pedagógica. E isso pode ser a raiz das dificuldades dessa funçáo, uma vez que não foram formados e treinados para praticar e refletir sobre essa atividade.

Em relação à organização e carga horária, os relatos traduzem falta de tempo para realização de atividades profissionais e pessoais devido à carga horária extenuante. Esta já era uma expectativa dos ingressantes ao iniciarem a Residência.

Depois de 12 horas, você vai conseguir chegar em casa e você vai estudar? E você vai ter vida social? (Egressa 4)

Aplicadas as 60 horas semanais, o residente em tese dedica ao programa dez horas diárias em seis dias da semana, tendo um dia de folga remunerada. Uma jornada dessa, ainda que associe atividades práticas e teórico-práticas, é altamente extenuante, apontando para uma lógica inclinada à exploração do trabalho, em detrimento de uma proposta de formaçáo para o trabalho em saúde. Ainda que haja particularidades no trabalho do residente, estas não alteram sua condição de trabalhador, mesmo que temporário. Desta feita, as 60 horas semanais são uma forma de intensificação da exploração do trabalho e são incompatíveis com as propostas de formaçâo inscritas na RMS (SILVA, 2018).

O ambiente hospitalar constitui importante cenário de formação no campo da assistência/cuidado às pessoas. É neste local que o estudante conhece as rotinas básicas do cuidado e todas as demais atribuições da profissão (SELTENREICH, 2017). No que tange à estrutura do HU-UFPI, foi unânime que é um hospital muito equipado e com uma excelente estrutura, essa também foi a expectativa relatada pelos residentes no início da RMS-UFPI.

A gente quando vai pra outro hospital público que seja do SUS ou filantrópico, é incomparável a estrutura daqui, tanto de limpeza, quanto de equipamento. (E1)

\section{Considerações finais}

Esta pesquisa contribuiu para a discussão acerca da temática das Residências Multiprofissionais em Saúde, visto ser este um espaço profícuo para a formação de profissionais dentro dos princípios e diretrizes do SUS e, consequentemente, para a mudança do modelo assistencial hegemônico baseado na lógica medicocêntrica. A RMS é um avanço na ressignificação deste modelo e na busca pela concretização de novas propostas e práticas em saúde. $\mathrm{O}$ estudo promove reflexôes acerca de práticas 
pedagógicas, do trabalho em equipe multiprofissional e do manejo com residentes que, apesar de formados, estáo em processo de especialização. É preciso valorizar os relatos desses profissionais e pensar em estratégias de melhoria do ensino em serviço.

O sucesso do Programa de Residência Multiprofissional em Saúde relacionase diretamente à adesão dos profissionais por ele formados, à atuação em equipe multiprofissional e à satisfação desses pós-graduados quanto a esse tipo de formação. Essa pesquisa promoveu uma avaliação da RMS-UFPI, por meio da comparação entre relatos de ingressantes e de egressos. Desta feita, percebeu-se que algumas expectativas iniciais dos residentes foram atingidas pelos egressos, e outras não. As percepçóes dos egressos evidenciaram que expectativas quanto ao conhecimento teórico, trabalho multiprofissional, relação com residentes da RMS, com profissionais e preceptores foram aquém do esperado inicialmente.

Já as expectativas quanto ao preparo e autoconfiança profissional, conhecimento prático, inserção no mercado de trabalho, carga horária e infraestrutura do HUUFPI foram atingidas no transcorrer dos dois anos desse tipo de pós-graduação.

O interesse deste estudo se deteve na avaliação da RMS-UFPI como uma forma de melhorar o processo de formação e a atuação dos residentes multiprofissionais, e não apenas para a efetivação de um trabalho científico. Portanto, o assunto não se esgota, permitindo que novas contribuiçóes possam emergir.

As dificuldades e insatisfaçóes apontadas nessa pesquisa, por parte de residentes e egressos, demonstram que há desafios a serem superados no âmbito do processo ensino-aprendizagem e das relaçôes interprofissionais. Apesar disso, a RMS-UFPI está em construção e, apesar de suas limitações, tem auxiliado a difundir novos saberes e fazeres no campo da saúde. Logo, se vislumbra melhores avaliações por parte dos seus formados no futuro.

Um ponto crucial na RMS é a nítida necessidade de capacitação de preceptores e tutores, que cumprem um papel de grande importância dentro deste processo de formação. Na perspectiva de aprimorar suas competências, conhecimento teórico e prático, a humanização e ética, a educação permanente desses profissionais possibilitará uma melhoria tanto para suas atividades de preceptoria, quanto para suas funçóes assistenciais.

Destaca-se também a necessidade de comunicação, integração e ajuda mútua entre os profissionais do hospital, sejam eles de quaisquer áreas, e os residentes. Esse trabalho conjunto é primordial para a superação do modelo biomédico e para 
a conquista da integralidade tão sonhada pelo SUS e da qualidade da assistência prestada. Reitera-se que o residente, apesar de ser um profissional formado, é também um profissional em especialização. Portanto, ele precisa do suporte de ensino e da contribuição destes profissionais do serviço. ${ }^{1}$

\section{Referências}

ARNEMANN, C. T. et al. Práticas exitosas dos preceptores de uma residência multiprofissional: interface com a interprofissionalidade. Interface, v. 22, supl. 2, p.1635-1646, 2018.

BAQUIÃO, A. P. S. S. et al. Percepções de residentes multiprofissionais de saúde sobre a interdisciplinaridade. Saúde e Pesquisa, v. 12, n. 1, p. 187-196, abr-jan. 2019.

BARDIN, L. Análise de conteúdo. São Paulo: ed. 70, 1977.

BRASIL. Ministério da Saúde. Portaria no 198/GM/MS, de 13 de fevereiro de 2004. Institui a política nacional de educação permanente em saúde como estratégia do Sistema Único de Saúde para a formação e o desenvolvimento de trabalhadores para o setor e dá outras providências. Diário Oficial da União, Poder Executivo, Brasília, DF, 2004, seção 1, p. 37-41.

. Ministério da Saúde. Residência Multiprofissional em Saúde: experiências, avanços e desafios. Brasília, 2006.

Ministério da Saúde. Portaria no 1.996, de 20 de agosto de 2007. Dispóe sobre as diretrizes para a implementação da Política Nacional de Educação Permanente em Saúde e dá outras providências. Brasília. Diário Oficial da União, Poder Executivo, Brasília, DF, 20 ago. 2007, seção 1, p.34-38.

. Ministério da Educação/ Ministério da Saúde. Portaria Interministerial MEC/MS no 1077, de 12 de novembro de 2009. Dispóe sobre a Residência Multiprofissional em Saúde e a Residência em Área Profissional da Saúde, e institui o Programa Nacional de Bolsas para Residências Multiprofissionais e em Área Profissional da Saúde e a Comissão Nacional de Residência Multiprofissional em Saúde. Diário Oficial da União, Poder Executivo, Brasília, DF, 13 nov 2009, seção I, p.7.

CAREGNATO, R. C. A.; MUTTI, R. Pesquisa qualitativa: análise de discurso versus análise de conteúdo. Texto contexto enfermagem, v. 15, n. 4, p. 679-84, 2006.

CASANOVA. I. A.; BATISTA, N. A.; MORENO, L.R. A educação interprofissional e a prática compartilhada em programas de residência multiprofissional em saúde. Interface, v. 22, supl. 1, p.1325-1337, 2018.

CAVALCANTI, J. L.; SANT’ANA, J. M. B. A preceptoria em um programa de residencial multiprofissional em oncologia: carência e dificuldades. Revista Eletrônica Gestão \& Saúde, v. 5, n. 3, p. 1045-1054, 2014. 
CECCIM, R. B. Desenvolvimento de competências no trabalho em saúde: educação, áreas do conhecimento e profissóes no caso da saúde. Revista Tempus Actas de Saúde Coletiva, v. 6, n. 2, 2012 .

COREMU/UFPI. Comissão de Residência Multiprofissional em Saúde e em Área Profissional da Saúde. Universidade Federal do Piauí. Resolução CEPEX/UFPI nº155/13. Regimento Geral da Comissão de Residência Multiprofissional em Saúde e em Área Profissional da Saúde da UFPI. Teresina-PI, 3 ago. 2017. Disponível em: htpps://ufpi.br/regimento-coremu Acesso em: 3 jun 2019.

DEGIOVANI, M. V. A residência multiprofissional no Hospital São Paulo (HU-UNIFESP): percepção dos residentes sobre o processo de ensino em saúde e atuação em equipe interprofissional. 2017. 88f. Dissertação (Mestrado em Ensino em Ciências e Saúde) - Escola Paulista de Enfermagem, Universidade Federal de São Paulo, São Paulo, 2017.

DIAS, A. R. N. et al. Preceptoria em saúde: percepçóes e conhecimento dos preceptores de uma unidade de ensino e assistência. Revista Educação, n. 19, p. 83-99, jun-ago, 2015.

FARIAS, T. C. B. Formação interdisciplinar: contribuições da Residência Multiprofissional em Saúde. 2016. 178f. Tese (Doutorado em Educação, Arte e História da Cultura) - Universidade Presbiteriana Mackenzie, São Paulo, 2016.

FEUERWERKER, L. C. M.; CECÍLIO, L. C. O. O hospital e a formação em saúde: desafios atuais. Ciência \& Saúde Coletiva, v. 12, n. 4, p. 965-971, 2007.

JREIGE, C. M. Programa de Residência Multiprofissional em Saúde: um estudo sobre os efeitos na crença, satisfação e comprometimento. 2013. 65f. Dissertação (Mestrado em Psicologia Social). Universidade de Brasília. Brasília, 2013.

LANDIM, S. A.; SILVA, G. T. R.; BATISTA, N. A. A residência em saúde da família: vivência hospitalar dos enfermeiros. Revista Baiana de Enfermagem, Salvador, v. 26, n. 1, p. 375-386, jan-abr. 2012.

OLIVEIRA, J. B. et al. Influência da residência multiprofissional na vida profissional de egressos. Revista Inova Saúde. Criciúma, v. 6, n. 1, jul, 2017.

PERES, R. S. et al. O trabalho em equipe no contexto hospitalar: reflexões a partir da experiência de um programa de Residência Multiprofissional em Saúde. Em extensão, v. 10, n. 1, p. 113-120, jan-jun. 2011.

SANCHES, V. S. et al. Burnout e qualidade de vida em uma Residência Multiprofissional: um estudo longitudinal de dois anos. Revista Brasileira de Educação Médica, v. 40, n. 3, p. 430-436, 2016.

SELTENREICH, L. S. Competências do enfermeiro na prática da preceptoria na Residência Multiprofissional em Saúde. 2017. 69f. Dissertação (Mestrado em Enfermagem) - Faculdade de Medicina, Universidade Estadual Paulista “Júlio de Mesquita Filho”, São Paulo, 2017. 
SILVA, C. T. et al. Educação permanente em saúde: percepção de profissionais de uma residência multidisciplinar. Revista de Enfermagem da UFSM, v. 3, n. Esp, p. 627-635, 2013.

SILVA, J. C. et al. Percepção dos residentes sobre sua atuação no programa de residência multiprofissional. Acta Paulista de Enfermagem, v. 28, n. 2, p. 132-8, 2015.

SILVA, L. B. Residência Multiprofissional em Saúde no Brasil: alguns aspectos da trajetória histórica. Revista Katálysis, Florianópolis, v. 21, n. 1, p. 200-209, jan-abr. 2018.

SILVEIRA, L. H. A. Avaliação do conhecimento dos residentes de um Programa de Residência Multiprofissional em Saúde referente ao "Contrato Didático". 2011. 148p. Dissertação (Mestrado em Saúde da Criança e do Adolescente) - Faculdade de Medicina, Universidade Federal do Rio Grande do Sul, Porto Alegre, 2011.

SOUZA, S. V.; FERREIRA, B. J. Preceptoria: perspectivas e desafios na Residência Multiprofissional em Saúde. ABCS Health Sciences, v. 44, n. 1, p.15-21, 2019.

TORRES et al. Estado da arte das residências integradas, multiprofissionais e em área profissional da Saúde. Interface. Botucatu, v. 23, e. 170691, 2019.

\section{Nota}

${ }^{1}$ E. M. Carneiro: pesquisa de campo, coleta de dados, análise e interpretação dos dados, e redaçáo do texto. L. M.S. Teixeira: análise e interpretação dos dados, e revisão do texto. J. I. S. Pedrosa: análise e interpretação dos dados, revisão do texto e orientou o estudo. Este trabalho é parte da produção acadêmica de uma dissertaçáo de mestrado acadêmico em Ciências e Saúde, na linha de pesquisa de Análise de Políticas, Sistemas, Programas e Serviços de Saúde - Departamento de Ciências da Saúde - Universidade Federal do Piauí. 


\section{Abstract}

\section{The Multiprofessional Residency in Health: newcomers' expectations and students' perceptions}

The Multiprofessional Residency in Health is a type of in-service training that is based on learning technical and relational attributes through daily practice, with a view to improving the SUS. This study aims to understand the expectations of multiprofessional residents and compare them with the perceptions of graduates. The qualitative method was used and, for data production, a non-directive interview was conducted with 12 freshmen and a focus group with seven graduates. The newcomers' reports generated a general category "expectations", from which four subcategories were unveiled: personal, professional, relational, structural / organizational. The perceptions produced by the graduates showed that expectations regarding theoretical knowledge, multidisciplinary work, relationship with residents of the MRH, with professionals and tutors were below expectations. Expectations regarding professional preparation and selfconfidence, practical knowledge, insertion in the labor market, workload and hospital infrastructure were met over the course of two years of this type of postgraduate degree. Knowledge of residents' expectations and perceptions allows for an assessment of the Residency and can provide opportunities for improvements in the planning and execution of teaching, and, consequently, in the quality of the program.

Keywords: Multiprofessional Residency; Residency in Health; health education; in-service training. 